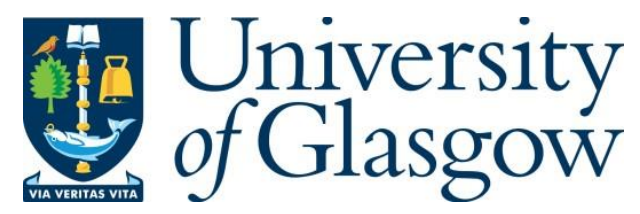

Yuan, Z., Huang, J., Zao, Z., Zahid, A., Heidari, H., Ghannam, R. and Abbasi, Q. H. (2019) A Compact Wearable System for Detection and Estimation of Open Wound Status In Diabetic Patient. In: IEEE Asia Pacific Conference on Postgraduate Research in Microelectronics and Electronics (PrimeAsia 2018), Chengdu, China, 26-30 Oct 2018, pp. 60-63. ISBN 9781538695913.

There may be differences between this version and the published version. You are advised to consult the publisher's version if you wish to cite from it.

http://eprints.gla.ac.uk/168791/

Deposited on: 13 September 2018

Enlighten - Research publications by members of the University of Glasgow http://eprints.gla.ac.uk 


\title{
A Compact Wearable System for Detection and Estimation of Open Wound Status In Diabetic Patient
}

\author{
Zhengnan Yuan ${ }^{1}$, Jiaxing Huang ${ }^{1}$, Zhiqin Zhao ${ }^{1}$, Adnan Zahid ${ }^{2}$, Hadi Heidari ${ }^{2}$, Rami Ghannam², \\ Qammer H. Abbasi \\ ${ }^{1}$ University of Electronic Science and Technology of China, Chengdu, China \\ ${ }^{2}$ School Electronics and Nanoscale Engineering, University of Glasgow, G12 8QQ, Glasgow, UK \\ Email: $\{2168525 Y, 2168545 H\} @$ \}student.gla.ac.uk, zqzhao@uestc.edu.cn, a.zahid.1@ research.gla.ac.uk, \{Hadi.Heidari, Rami \\ Ghannam, Qammer.Abbasi\}@glasgow.ac.uk
}

\begin{abstract}
In this paper, a new smart health embedded system that can notify users the status of an open wound to assure correct cicatrisation in real-time for ulcer foot in diabetes prevention has been designed. Specifically, this system monitors the healing process through the saturation of exudate in the absorbent dressing and the pathogen of infection by estimating the top gas of wound based on the various bacteria's metabolites. The collected information has been transmitted on portable devices in real time to inform the patient the current condition of wound and give advice. Finally, the algorithm of diabetes wound healing process is explored in this work, which can also be applied for related medical research in the diabetes preventions. The measurement results have an error of $0.9 \%$ and $2.3 \%$, respectively for temperature and humidity in detection of cicatrisation. In the evaluation of pathogen of wound infection, the error of predicting the concentration of different gases (Sulfo-compound, Ethanol and Aldehyde) was only $2.8 \%$.
\end{abstract}

Keywords-open wound healing estimation, embedded system, bacteria detection, and diabetes, wearable

\section{INTRODUCTION}

Stand in the continually flowing rivers of nature, no one is capable of escaping from greying ages, deaths and health problems. The better medical system is required to couple with prolongation of per capita life, decline of the birth rate and climbing health awareness. Health, one of the threshold topics in all walks of life, is not merely based on enough capital or public services. Considering cloud computing intelligent equipment technology, artificial intelligence system and embedded system, smart electronic medical treatment (e-health [1]) is urgently demanded to offer everyone a more equal and comfortable medical service. For instance, balance the medical resources, expand the patients' database, and mitigate the tense relationship between doctors and patients.

The innovation of this paper lies in the utilizing and deployment of IoT technology that includes wireless communication, parameters detection and status estimation (based on Support vector machine) in open wound healing examination for diabetic patients on a compact embedded system [2]. Previously, the intention status can only be estimated by the doctor which causes inconvenience, medical

resources of society occupation and unnecessary costs of patient [3]. Nowadays, in detecting and recording physical vital signs, widespread application of IoT technology generates a spate of products, be it Keep, Fitbit and Samsun Health [4] etc. However, for medical support, only a few products with limitations of importability, expense and short lifetime have been invented [5]. During the healing of an open wound in diabetics, in previously, it would be impossible to use tiny embedded devices for basic parameters detection and intention status estimation due to the technological limitations in components integration, wireless communication and portable devices. In those years, diabetic patients with open wound are advised to go to the hospital for periodical wound examination in order to prevent massive necrosis of cells which could be degraded into amputation [6]. The device explored in this report devotes to provide users with less complication, instant treatment notification, and convenience.

In this paper, an advanced portable smart device, an embedded system for open wound intention status detection and notification in real time is designed and constructed. Unlike normal e-health devices, the system performs well in parameters detection and has the capability to predict the intention status which offers patients more personalized suggestions for prevention of wound degradation by SVM [7] (e.g. inflammation, amputation, and organ failure).

Comparing this smart health device with congeneric products, first of all, the number of IoT devices for venous ulcer and other lower extremity wound infection is relatively lower. Most advanced productions be it 'eZscan' of Impeto Medical [8], 'LifeScan' of Johnson \& Johnson and 'One Drop' exploited by Jeff Dachis [9] concentrate on smart devices for monitoring and estimating sudoriferous secretion function, blood glucose level, diet-style, and exercise record to promote the therapy. Explicitly, 'eZscan' is a conductance analyzer for detecting the risk of diabetes through sudoriferous secretion function noninvasively. 'LifeScan' focus on quick measurement of blood glucose value and instant notification. 'One Drop' combines states of blood glucose, food and physical activity with Alexa phonetic assistant of Amazon. However, the states of wounds are rarely notified for the patients who are suffering from timeconsuming subsequent visit and inflammation.

Secondly, compared with other wound estimation device, in one aspect, the compact embedded system in this paper can not only estimate the parameters of the environment (humidity and temperature) surrounded the wound. In another aspect, it 
also analysis the gas released by various states of healing process which is the functions of electronic nose for notifying the user predicted intension states with smaller error $(2.8 \%)$ in understandable graph and real-time notification on the 'iHealing' APP of mobile phone.

Thirdly, the accuracy in detection of humility and temperature is desired. In this part of the electronic nose, the product in the report uses the concentration of Ethanol, Aldehyde, sulfocompound to predict the location and growth of Pseudomonas aeruginosa, Staphylococcus aureus and Escherichia coli in various intensions status. Specifically, the gas released by these bacteria is different which can be estimated and classified by the data recorded from the gas sensors. The rate of detection error for both the embedded part are all small enough that can reach the current lowest error of other similar productions, respectively. The research of Gardner indicates that the error rate of diagnosis is $7.8 \%$ with the application of electronic nose.

Fourthly, although SVM does not perform well in large scale data leaning, it has strong ability of approximation and generalization compared with normal neural network.

\section{SYSTEM DESIGN}

\section{A. Wearable Item}

The extrinsic features and material technology can directly affect the quality of equipment. Design of the sole is based on the healing process of open wound and the comfortability of the users. Specifically, various cells cooperate with different molecules to complete the complex and subtle healing process that contains coagulation period. Considering the requirements of medical theory and expectations of humanized design, the 3D Max figure of the handmade sole is shown in figure 1 (a) and (b).

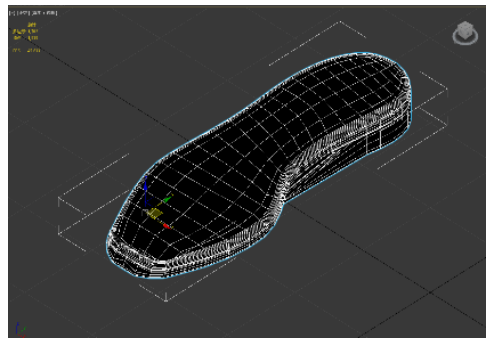

(a)



(b)
Fig. 1. Depition of Shoe sole mode1 (a) 3DMax model (b) Actual sample sole

\section{B. Electronic System}

As shown in figure 2, This whole system consists of two parts: the first part is the embedded system which is deployed in the shoes, and the second part is the host computer (smartphone) which shows users information. The core of the hardware of the first part is Arduino Uno which manages the power supply circuit, sensor circuit and Bluetooth circuit. In the run time of the first part, five groups of sensors (temperature sensors, humidity sensors, pressure sensors, pulse and $\mathrm{SpO} 2$ sensor and gas sensors) capture the physical vital signs around the wound and transfer this information into analogue signals with first filtering. After the MCU receiving the analogue signals from sensors, these signal is filtered again and transferred into digital form in order to be sent to Bluetooth module through UART serial port. Next, the Bluetooth modulate these signals and send them to the builtin Bluetooth adapter of the host computer (smartphone). Finally, this data will be processed based on the mathematical model constructed in this paper to show the condition of the wound (e.g. warn the patient when some of the parameters overweigh the threshold and give some advice).

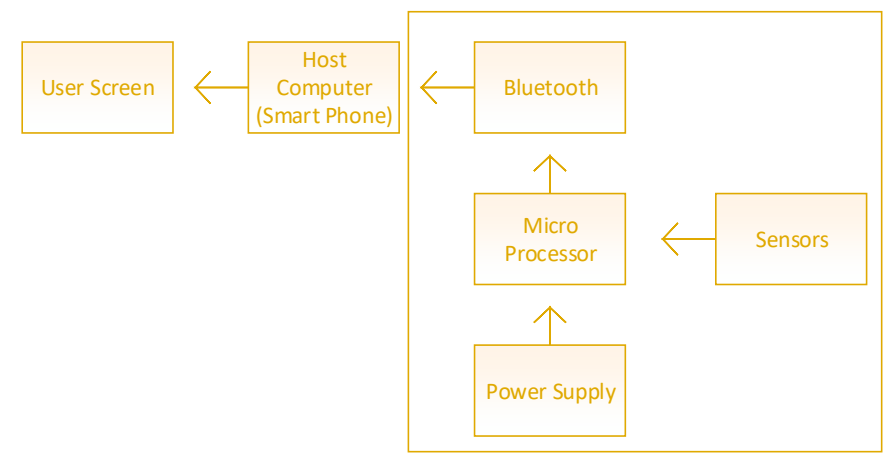

Fig. 2. Flow chart illustation of the proposed designed wearable system

\section{Sensors}

1) Temperature sensor, humidity sensors and pressure sensor, pulse and $\mathrm{SpO} 2$ sensor.

2) Gas sensor: In order to prevent the wound from infection mentioned in section 2, three types of most infectious bacteria have been monitored, be it Staphylococcus aureus, Pseudomonas aeruginosa and Staphylococcus epidermidis, with the infection probability $28.2 \%, 25.1 \%$ and $20.4 \%$ respectively. According to the table [10] shown below, the staples of Staphulococcus Aureus are Ethanol and Ammonia. Those of Pseudomonas Aeruginose are 2nonketone, 2-amino acetophenone, 2-butanone, methyl ketone, 2-heptanone, butanol, isoamyl alcohol, iso-butanol and sulphur containing compounds. Escherichia Coli mainly products alcohol, decyl alcohol, 12-akanols, octanol, 1propanol, methane-mercaptan, amyl alcohol, acetaldehyde, formaldehyde, acetophenone and hydrogen sulfide. By comparing those major products with the measurable parameters, the sensors have, TGS 822, QS-01 and MQ138 are selected to provide data for the logistic regression classifier and to notify users the intention status of the wound.

TABLE I. PATHOGENS IN WOUND INFECTION AND THEIR METABOLITES

\begin{tabular}{|l|l|c|}
\hline \multicolumn{1}{|c|}{ Bacteria } & $\begin{array}{c}\text { occurrence } \\
\text { probability }\end{array}$ & Volatile products \\
\hline $\begin{array}{l}\text { Staphylococcus } \\
\text { aureus }\end{array}$ & $29.4 \%$ & $\begin{array}{l}\text { Isobutanol, isopentyl acetate, } \\
\text { 1-undecene, methyl ketones, }\end{array}$ \\
\hline
\end{tabular}




\begin{tabular}{|c|c|c|}
\hline Bacteria & $\begin{array}{l}\text { occurrence } \\
\text { probability }\end{array}$ & Volatile products \\
\hline & & $\begin{array}{c}\text { ammonia, ethanol, } \\
\text { trimethylamine, 2,5 } \\
\text { dimethylpyrazine } \\
\text { isoamylamine, } \\
\text { 2-methylamine, acetic acid }\end{array}$ \\
\hline $\begin{array}{l}\text { Pseudomonas } \\
\text { aeruginosa }\end{array}$ & $26.1 \%$ & Pyruvate \\
\hline $\begin{array}{l}\text { staphylococcus } \\
\text { epidermidis }\end{array}$ & $21.3 \%$ & Acids, alcohols \\
\hline
\end{tabular}

TABLE II. SENSTIVE GAS OF GAS SENSOR

\begin{tabular}{|l|c|}
\hline \multicolumn{1}{|c|}{ Sensor } & Volatile products \\
\hline TGS822 & $\begin{array}{c}\text { Organic solvent vapor, Methane, Carbon monoxide, } \\
\text { Isobutane, Hexane, Benzenes, Ethanol, Acetone }\end{array}$ \\
\hline MQ138 & Alcohol, Aldehyde, Ketone, Aromatic hydrocarbon \\
\hline QS-01 & $\begin{array}{c}\text { VOCs, Air pollutants, Volatile organic compounds, } \\
\text { Ethanol, Carbon monoxide, Ammonia, Hydrogen, } \\
\text { Methane, Isobutane }\end{array}$ \\
\hline
\end{tabular}

\section{Circuit, PCB and Acrylic protection}

For the stability, as shown in figure 3 , figure 4 (a) and (b), integration and wearability of this whole system, we design a PCB to integrate all the component into a package and use acrylic board to protect this system from external pressure.

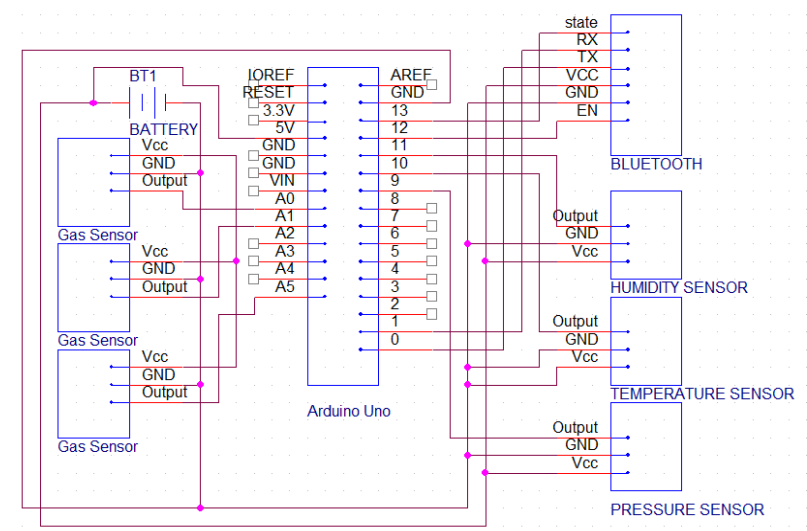

Fig. 3. Schematic represenation of proposd design circuit system

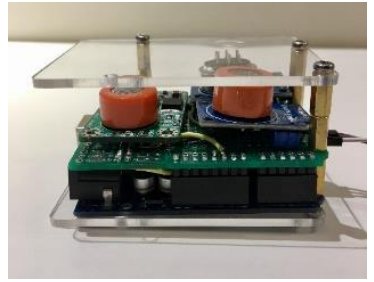

(a)

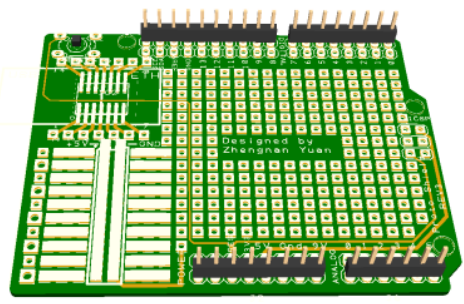

(b)
Fig. 4. (a) Real picture (b) PCB 3D view

\section{E. Application}

For data processing and notification to patient, we compile and build an application named "iHealing" to receive the data from embedded, input this data into the mathematical model and inform the patient of the current condition of their wound and then advice based on the results of the mathematical model. The environment of writing this application is Android Studio 3.0.1, gradel4.1, Android SDK Platform-tools 27.0.1, Android SDK Build-tools 27.0.3, and the test environment is Samsung SM-G9350 with Android 6.0.1, API 23. This application has five functions: (1) ask the permission of using Bluetooth and receive the data from embedded system though through Bluetooth. (2) Processing data (3) Show the UI to users with basic information (4) store this data (5) notify the users when the threshold has been exceeded or bacteria has been detected. In the data processing, the difference between current values of parameters (temperature, humidity and gas concentration etc.) and threshold values are calculated to determine whether to warn the patient to check or keep standby. The data from three types of gas sensors is sent to a logistic regression classifier to make the final decision whether the wound is in the inflammation phase or not based on the concentration of volatile products of bacteria. The information of the application is shown in figure 5 (a) and (b):



(a)

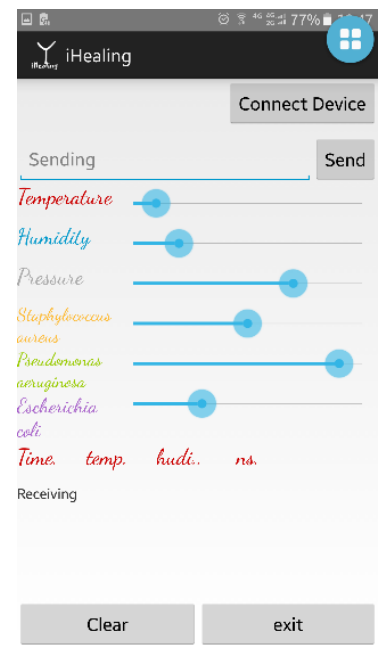

(b)
Fig. 5. (a) Notification (b) User interface of iHealing

\section{RESULTS AND ANALYSIS}

As shown in fig, all the components have been integrated into a package with the size of $6.6 \mathrm{~cm} \times 5.3 \mathrm{~cm} \times 3.5 \mathrm{~cm}$. The bottom and top of this package are two acrylic board with thickness of $0.5 \mathrm{~cm}$ to protect this whole system. The information is shown in figure 6 (a) and (b). 


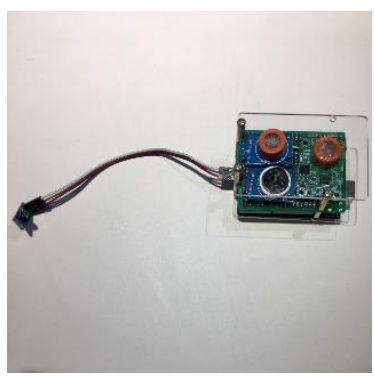

(a)



(b)
Fig. 6. (a) Top view of whole system (b) Receive data on user interface

For the results and analysis, we test this system in an ideal and a real environment. In the part of ideal environment testing, 1000 groups data are selected to calculate the accuracy of basic parameters, be it temperature, humidity, $\mathrm{SpO} 2$ and pressure.

TABLE III. SENSTIVE GAS OF GAS SENSOR

\begin{tabular}{|l|c|}
\hline \multicolumn{1}{|c|}{$\begin{array}{c}\text { Basic } \\
\text { parameters }\end{array}$} & Error $(\%)$ \\
\hline temperature & 0.9 \\
\hline humidity & 2.3 \\
\hline $\mathrm{SpO} 2$ & 5.8 \\
\hline pressure & 1.5 \\
\hline
\end{tabular}

In the part of real environment testing, 1000 groups data are selected to calculate the accuracy of predicted parameters and information, for instance, the concentration of Ethanol, Aldehyde, sulfocompound and the predicted intention status.

TABLE IV. SENSTIVE GAS OF GAS SENSOR

\begin{tabular}{|l|c|}
\hline \multicolumn{1}{|c|}{ Prediction } & Error $(\%)$ \\
\hline concentration of Ethanol & 8.7 \\
\hline concentration of Aldehyde & 12.8 \\
\hline concentration of sulfocompound & 3.4 \\
\hline the predicted intention status & 2.8 \\
\hline
\end{tabular}

From error data upon, it is obvious that the basic parameters have a little error in the ideal environment testing which means this advanced embedded system has the capability to detect the accurate value of basic parameters if the soles are placed in right position. According to the error results of predicted parameters and information tested in real environment, the detection of sulfocompound and the prediction of intention status shows good performance. As for the detection of Ethanol and Aldehyde, they are not accurate but acceptable.

\section{CONCLUSION}

An advanced portable smart device, an embedded system for open wound intention status detection and notification in real time is designed and constructed. Unlike normal e-health devices, this system has desired accuracy in parameters detection and has the capability to predict the intention status which offers patients more personalized suggestions for the prevention of wound degradation (e.g. inflammation, amputation, and organ failure etc).

\section{ACKNOWLEDGMENT}

This work is partially supported by the final year project of Glasgow College, UESTC.

\section{REFERENCES}

[1] Andreassen, H. K., Bujnowskafedak, M. M., Chronaki, C. E., Dumitru, R. C., Pudule, I., \& Santana, S., et al. (2007). European citizens' use of e-health services: a study of seven countries. Bmc Public Health, 7(1), 53.

[2] Wu, S., Wang, C., \& Zhang, G. (2015). Has china's new health care reform improved efficiency at the provincial level? evidence from a panel data of 31 chinese provinces. Journal of Asian Public Policy, 8(1), 36-55.

[3] Cullity, B. D. (1978). Element of x-ray diffraction. American Journal of Physics, 25(6), 50-50.

[4] Pahlm, U. S., Pahlm, O., \& Wagner, G. S. (1996). The standard 11-lead ecg * : neglect of lead avr in the classical limb lead display. Journal of Electrocardiology, 29(Suppl 1), 270-274.

[5] . Berger, H., Bradaczek, H. A., Pianowski, H., \& Bradaczek, H. (2000). A new quartz-blank sorting machine including optical and extended Xray inspection. Frequency Control Symposium and Exhibition, 2000. Proceedings of the 2000 IEEE/EIA International (pp.247-249). IEEE.K. Elissa, "Title of paper if known," unpublished.

[6] Mcnittgray, M. F. (2007). Computed tomography — an increasing source of radiation exposure - nejm. New England Journal of Medicine,357(22), 2277-84.

[7] Lehmann, L. A., Alvarez, R. E., Macovski, A., Brody, W. R., Pelc, N. J., \& Riederer, S. J., et al. (1981). Generalized image combinations in dual kvp digital radiography. Medical Physics, 8(5), 659-667.

[8] Fox, M. D., \& Raichle, M. E. (2007). Spontaneous fluctuations in brain activity observed with functional magnetic resonance imaging. Nature Reviews Neuroscience, 8(9), 700-11.

[9] . Liao, X., \& Xiao, S. (1999). Application of b ultrasonic examination in laparoscopic cholecystectomy. Chinese Journal of Ultrasound in Medicine.

[10] Anthilingam, P. (2008). Validation of an instrument to measure cognitive function in patients with heart failure. Dissertations \& Theses - Gradworks. 